\title{
A Study on Sexual Unwellness in Old Age: Assessing a Cross-National Sample of Older Adults
}

\author{
Sofia von Humboldt ${ }^{1}$, Sara Silva ${ }^{1} \&$ Isabel Leal $^{1}$ \\ ${ }^{1}$ William James Center for Research, ISPA-Instituto Universitário, Lisbon, Portugal \\ Correspondence: Sofia von Humboldt, William James Center for Research, ISPA-Instituto Universitário, Rua \\ Jardim do Tabaco, 34, 1149-041, Lisbon, Portugal. Tel: 351-21-881-1700. E-mail: sofia.humboldt@gmail.com
}

Received: July 28, 2017

Accepted: August 8, 2017

Online Published: August 27, 2017

doi:10.5539/res.v9n3p207

URL: http://doi.org/10.5539/res.v9n3p207

\begin{abstract}
Objectives: To analyze the contributors to Sexual Unwellness (SU) and to explore the latent constructs that can work as major determinants in SU for a cross-national older community-dwelling population.

Methods: Study design: Complete data were available for 109 English and Portuguese older adults, aged between 65 and 87 years old $(M=70.1, S D=5.99)$. Data was subjected to content analysis. Representation of the associations and latent constructs were analyzed by a Multiple Correspondence Analysis. A socio-demographic and health questionnaires were completed, assessing participants' background information. Interviews were completed, focused on the contributors to SU.

Results: The most frequent response of these participants was "lack of intimacy and affection" (25.1\%) whereas "poor sexual health" was the least referred indicator of SU (11.2\%). A two-dimension model formed by "poor affection, intimacy and sexual health", and "poor general health and financial instability" was presented as a best-fit solution for English older adults. SU for Portuguese older adults were explained by a two-factor model: "daily hassles and health issues", "poor intimacy and financial instability".

Conclusions: These outcomes uncovered the perspective of older adults concerning SU and the need of including these factors when considering the sexual well-being of older cross-national samples.
\end{abstract}

Keywords: community-dwelling older adults, content analysis, multiple correspondence analysis, qualitative study, sexual unwellness

\section{Introduction}

The worldwide number of older individuals is growing faster than the number of people in other age groups. Although some authors suggest that approximately one third of old persons have aged well, the rapid and uneven aging of the population will continue to bring challenges to researchers and health professionals, concerning the health and aging well of this population group (Fernández-Ballesteros, 2010). Since older adults may remain sexually interested and capable into their 90 s, the diversity of this group, with respect to their health and well-being, must be taken into account, including the aspects related to their Sexual Well-Being (SWB) (United Nations, 2015).

SWB has been defined as the cognitive and emotional evaluation of an individual's sexual life, and can be assessed in terms of satisfaction judgments across diverse domains, such as, emotional and physical aspects of relationships, sexual functioning and other aspects of relative importance of sexuality in the individual's life (Rosen \& Bachmann, 2008). Although SWB is frequently misunderstood and, neglected in old age (Kalra, Subramanyam, \& Pinto, 2011), it is an integral part of general well-being (Hooghe, 2012). Other authors suggest that SWB indicates the perceived quality of the individual's sexuality, including the sexual function, sexual satisfaction, sexual relations, body image, and the overall sexual life (Laumann et al., 2006). In a cross-cultural study, Laumman and his colleagues (2006) suggested that in relation to the four aspects of SWB (physical pleasure, emotional pleasure, satisfaction with sexual function and importance of sex), men showed consistently higher scores than women. In the same study, satisfaction with sexual function was related to emotional satisfaction and physical satisfaction. Additionally physical and emotional satisfaction showed the highest contribution to SWB, in comparison to the remaining factors (Laumman et al., 2006). In another cross-national study with older adults, affection and care, and sexual and physical health were the most prevalent indicators of 
SWB, while sexual touching, sexual intercourse ad sexual desire for others were least important for their SWB (von Humboldt, Leal, \& Monteiro, 2016). Despite the growing interest in SWB, most of the research has focused on the sexual function and sexual satisfaction, and less on the emotional and relational variables associated with SWB (Laumann et al., 2006).

Older adults maintain their intimacy and significant relations as they grow older, which may include an active, satisfying sex life. However, with the process of aging, a number of changes may cause sexual problems (Aldwin, Jeong, Igarashi, Choun, \& Spiro, 2014). In fact, older adults may face daily stresses and they may have the added concerns of the aging process, retirement, illness, disability, surgery, and lifestyle changes, all of which may lead to sexual difficulties.

Sexual Unwellness (SU) has been defined as including a lack of sexual satisfaction and an incapability to maintain their sexual relationships due to physical and mental health concerns (Syme, Cordes, Cameron, \& Mona, 2015). Although, older individuals identify their sexual life as important for their well-being and successful aging, a number of variables may affect their SWB and contribute to their SU including the following: losing one's partner, chronic health problems, menopause, low libido, problems of body image, problems of erectile functioning, and overall sexual dysfunctions (Syme et al., 2015). On study indicated that the lack of emotional or physical satisfaction with sex seems to be more linked to partner than individual health factors (Syme et al., 2015). Furthermore, some medication used for chronic illnesses may affect sexual functioning. Psychological factors, such as attitudes and beliefs, also appear to influence their sexual expression, which may in turn imply feelings of shame and embarrassment, and ultimately sexual restraint and abstinence (Syme et al., 2015). In addition, despite the fact that sexual concerns are widespread, older adults do not spontaneously verbalize them, suggesting that they prefer to report sexual functioning issues (Hirayama \& Walker, 2011).

Although there is a growing focus on older adults' aging well, factors associated with sexuality have been less explored in the literature (Hooghe, 2012). The scarcity of studies on this subject, together with rapid aging of the population put forward the need for more data describing the relation between SU and overall well-being of old people (Lee, Nazroo, O'Connor, Blake, \& Pendleton, 2014). Criticisms of the existing literature on older adults' sexuality include lack of a comparison group, cross-sectional nature of the studies, limited definitions of SWB and unwellness results, and lack of consideration of a more wide-ranging set of biopsychosocial risk factors (von Humboldt et al., 2016).

Perspectives of older adults concerning SU can contribute to the deepening of the aging self (Schwartz et al., 2014). Considering that SU in old age is self-perceived and that different meanings for their experiences are indicated in different cultures, qualitative research allows access to these perspectives of older adults (von Humboldt et al., 2016). However, there is still need for deepening the older adults' perceptions of SU as these may become relevant for health care and community interventions (von Humboldt et al., 2016). In view of the limited number of studies that focus this concept in old age, this study aims to help filling this gap. Therefore, the aim of this study was to analyze the main categories that contributed to cross-national community-dwelling older adults' SU; and to explore the latent constructs that can work as major contributors to SU.

\section{Materials and Methods}

\subsection{Participants}

The sample for this study is comprised by 109 non-institutionalized individuals, aged 65 years old and above ( $M=70.1, S D=5.99), 65.1 \%$ female, $69.7 \%$ married, and $67.0 \%$ professionally inactive.

The recruitment of participants was performed purposefully through life-learning centers message boards, community centers in the Lisbon metropolitan area and in the Algarve region (in Portugal). The two nationality groups are demographically homogeneous, as shown in Table 1.

After informed consent had been received in-person, participants went through a cognitive screening assessment. Participant eligibility comprised the following: (1) 65 years of age or older, (2) participants' score in the normal range on the Mini-Mental Status Exam (>26) (Folstein, M. F., Folstein, S. E., \& McHugh, 1975), and (3) no current treatment for sexual conditions. The American Psychological Association's standards on the ethical treatment of participants were followed. Table 1 shows the characteristics of the participants. 
Table 1. Distribution of the study's participants according to sociodemographic and health-related characteristics

\begin{tabular}{|c|c|c|c|c|c|c|}
\hline & \multicolumn{2}{|c|}{ English } & \multicolumn{2}{|c|}{ Portuguese } & \multicolumn{2}{|c|}{ Total } \\
\hline & $N$ & $\%$ & $n$ & $\%$ & $n$ & $\%$ \\
\hline$N$ & 53 & & 56 & & 109 & \\
\hline Age $(M ; S D)$ & $69.0(5.767)$ & & $71.3(6.046)$ & & $70.1(5.989)$ & \\
\hline \multicolumn{7}{|l|}{ Sex } \\
\hline Female & 32 & 60.4 & 39 & 69.6 & 71 & 65.1 \\
\hline Male & 21 & 39.6 & 17 & 30.4 & 38 & 34.9 \\
\hline \multicolumn{7}{|l|}{ Education } \\
\hline$<$ High school & 36 & 67.9 & 38 & 32.1 & 74 & 67.9 \\
\hline$\geq$ High school & 17 & 32.1 & 18 & 67.9 & 35 & 32.1 \\
\hline \multicolumn{7}{|l|}{ Marital Status } \\
\hline $\begin{array}{l}\text { Married or in a } \\
\text { relationship }\end{array}$ & 38 & 71.7 & 38 & 32.1 & 76 & 69.7 \\
\hline $\begin{array}{l}\text { Not married nor in a } \\
\text { relationship }\end{array}$ & 15 & 28.7 & 18 & 67.9 & 33 & 30.3 \\
\hline \multicolumn{7}{|l|}{ Professional Status } \\
\hline Active & 19 & 35.8 & 17 & 30.4 & 36 & 33.0 \\
\hline Inactive & 34 & 64.2 & 39 & 69.6 & 73 & 67.0 \\
\hline \multicolumn{7}{|l|}{ Family Annual Income } \\
\hline$\leq 15,000 €$ & 17 & 32.1 & 22 & 39.3 & 39 & 35.8 \\
\hline$>15,001 €$ & 36 & 67.9 & 34 & 60.7 & 70 & 64.2 \\
\hline \multicolumn{7}{|l|}{ Perceived Health } \\
\hline Good & 38 & 71.7 & 41 & 73.2 & 79 & 72.5 \\
\hline Poor & 15 & 28.7 & 15 & 26.8 & 30 & 27.5 \\
\hline
\end{tabular}

Note. Total sample: $n=109 ; S D=$ standard deviation.

\subsection{Measures and Procedure}

\subsubsection{Data Collection}

Participants were provided with a brief description of the study or in-person and were interviewed face-to-face in order to identify their considerations and opinions on SU. Semi-structured interviews were based on an interview guide and these lasted between 15 to 45 minutes.

Each interview began with a set of background questions, followed by one open-ended question: "I would like to understand what, in your point of view, may contribute to your sexual unwellness". All interviews were audiotaped and transcribed verbatim. Interviewers were not involved in previous relationship with the participants.

Upon completion of the interview, participants were asked to evaluate the schedule, and the interview process (see Figure 1). 


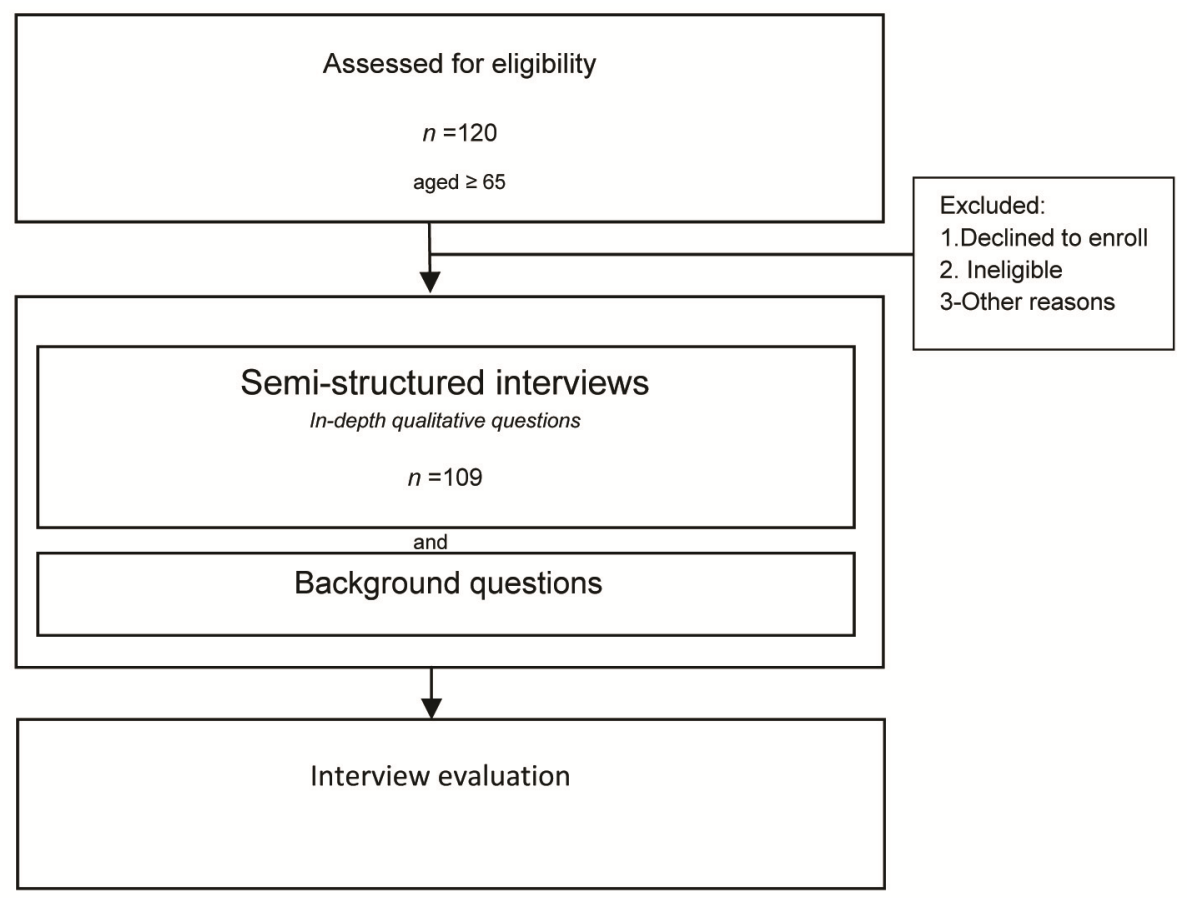

Figure 1. Overview of the data collection

\subsubsection{Data Analysis}

Data was analyzed using content analysis. The following procedures were followed: a) creation of major emergent categories, mutually exclusive, that reflected the 109 interviews, for the pre-existing category: indicators of SU; b) creation a list of coding cues; c) analysis of verbatim quotes and best fit descriptions for a given emergent category; d) definition of sub-categories, within and across the narratives, while preserving the principle of homogeneity of the category; and e) derivation of major emergent categories until the point of theoretical saturation was reached (Hsieh \& Shannon, 2015).

The structure of sub-categories and categories was exposed to an external review and critical feedback was found from reviewers with experience with older adults. An independent analysis of the 109 interviews was implemented by a jury of two psychologists (both faculty) and a concluding group co-resolution, regarding the categories was made. Reliability between researchers was assessed through the Cohen's Kappa. All categories showed a value above $.80(.865 \leq k \leq .914)$, hence suggesting a high agreement rate.

Representations of the associations between the emergent categories obtained from the narrative analysis, and latent constructs that can work as major indicators of older adults' perspectives of SU, were evaluated by a Multiple Correspondence Analysis (MCA). Statistic criteria included the following: (a) minimum of $5.0 \%$ of the total variance explained by each factor, and (b) minimum eigenvalue of 1 for each factor. Data were analyzed using SPSS for Windows (version 19.0; SPSS Inc., Chicago, IL).

The William James Center for Research coordination from ISPA-Instituto Universitário approved this study.

\section{Results}

\subsection{Content Analysis}

From the interviews with the older adults five categories emerged: (a) "poor sexual health"; (b) "daily hassles"; (c) "lack of intimacy and affection"; (d) "poor general health"; and (e) "financial instability".

The most frequent response of these participants was "lack of intimacy and affection" (25.1\%) while "poor sexual health" was the least referred indicator of SU (11.2\%) (see Table 2).

"Lack of intimacy and affection" was the most verbalized indicator of SU for English participants (26.1\%) and "daily hassles" for Portuguese participants (31.0\%). "Financial instability", was the least mentioned indicator of SU by Portuguese participants (9.4\%) and "poor sexual health" (11.8\%) for English participants (see Table 2). 


\subsection{Poor Sexual Health}

These participants indicated that having a poor sexual health, namely concerning the sexual function. Pain during penetration and vaginal dryness were verbalized by older women while erectile dysfunction and pain with penetration were reported by older men.

"I'm afraid of having sex with my husband because I feel pain most of the times. I would rather live 15 years shorter but have a good sex life with my husband, than live 15 years longer and feel lonely and not happy about my sex life." (Participant 87 )

"I no longer feel pain during sex. This really improved my sex life." (Participant 95)

\subsection{Daily Hassles}

Participants verbalized that daily hassles negatively contributed to their sexual well-being. In fact, common daily problems and unpredictable issues, related to their daily activities, accessibility, safety or comfort were related to SU.

"Daily problems affect my sex life. Feeling relaxed is very important to me. A simple problem in the house can be very stressful for me and may affect my sexual desire." (Participant 17)

"Every day problems emerge. I don't like to worry about petty problems but when I must solve them, these have an impact on eroticism and on my sexuality." (Participant 42)

\subsection{Lack of Intimacy and Affection}

These participants verbalized that the lack of demonstrations of affection and care, namely, touching, cuddling, affection words, holding hands, hugging and kissing, contributed to their SU.

"Before, my husband touched me a lot. I could feel that he enjoyed that and for me, it was a really pleasure too. Nowadays, we don't kiss anymore and I miss that." (Participant 19)

"I would love that my husband hugged me as much as before. I feel left out in our relationship." (Participant 58)

\subsection{Poor General Health}

Poor physical and mental health was pointed out by these participants as contributing to their SU. These participants reported that the decrease of sensory abilities and some physical conditions, such as depression and cardiovascular diseases, prosthetics and medication were indicated as contributing to their SU.

"My chronic condition implies some restrictions to my daily life. When I feel depressed, I do not want to think about sexual intercourse." (Participant 23)

"I have a chronic disease and that affects my sexuality." (Participant 34)

\subsection{Financial Instability}

Financial instability was indicated by the participants as contributing to their SU. Older adults reported that financial dependence, hassles and scarcity significantly affect their SU.

"We are both dependent of my children and that really affects our intimacy." (Participant 30)

"My savings are decreasing and I feel very insecure at the moment. I could say that since I retired and I do not work anymore, my sex life got worse." (Participant 34)

Table 2. Emergent categories resulting from content analysis of the pre-category "sexual unwellness"

\begin{tabular}{|c|c|c|c|c|c|c|}
\hline & \multicolumn{2}{|c|}{ English } & \multicolumn{2}{|c|}{ Portuguese } & \multicolumn{2}{|c|}{ Total } \\
\hline & $\begin{array}{l}\text { Category } \\
\text { frequency }\end{array}$ & $\begin{array}{c}\text { Category } \\
\text { percentage }\end{array}$ & $\begin{array}{l}\text { Category } \\
\text { frequency }\end{array}$ & $\begin{array}{c}\text { Category } \\
\text { percentage }\end{array}$ & $\begin{array}{l}\text { Category } \\
\text { frequency }\end{array}$ & $\begin{array}{l}\text { Category } \\
\text { percentage }\end{array}$ \\
\hline Poor sexual health & 34 & 11.8 & 31 & 10.8 & 65 & $11.2 \%$ \\
\hline Daily hassles & 55 & 19.2 & 89 & 31.0 & 144 & $24.8 \%$ \\
\hline $\begin{array}{c}\text { Lack of intimacy and } \\
\text { affection }\end{array}$ & 75 & 26.1 & 71 & 24.7 & 146 & $25.1 \%$ \\
\hline Poor general health & 67 & 23.3 & 76 & 26.5 & 143 & $24.6 \%$ \\
\hline Financial instability & 56 & 19.5 & 27 & 9.4 & 83 & $14.3 \%$ \\
\hline $\begin{array}{l}\text { Score of pre-category } \\
\text { "sexual unwellness" }\end{array}$ & 287 & 100.0 & 294 & 100.0 & 581 & 100.0 \\
\hline
\end{tabular}




\subsection{Multiple Correspondence Analysis of the Emergent Domains}

We used MCA for assessing the correlational structure of the category in our study: SU. Hence, outcomes suggest a model for SU, with diverse factors and factor loadings.

Results indicated a two-dimension model (accounting for $91.2 \%$ of total variance) composed by: "poor affection, intimacy and sexual health", and "poor general health and financial instability", as a best-fit solution for the English participants (see Table 3).

Moreover, outcomes also suggested a two-dimension model (accounting for $89.7 \%$ of total variance) composed by: "daily hassles and challenges" and "poor intimacy and financial instability", as a best-fit solution for the Portuguese participants (see Table 4).

Table 3. Three-dimensional representation for "sexual unwellness" for English older adults: factor loadings for each dimension, mean loadings and \% inertia (variance) explained

\begin{tabular}{cccc}
\hline & \multicolumn{3}{c}{ Dimensions } \\
\cline { 2 - 4 } Categories & $\begin{array}{c}\text { Poor affection, intimacy and } \\
\text { sexual health }\end{array}$ & $\begin{array}{c}\text { Poor general health and financial } \\
\text { instability }\end{array}$ & Mean \\
\hline Poor sexual health &. $\mathbf{7 4 3}$ & .169 & .456 \\
Daily hassles & .441 &. $\mathbf{4 9 5}$ & .468 \\
Lack of intimacy and & $\mathbf{. 7 4 7}$ & .111 & .429 \\
affection & .442 & & .470 \\
Poor general health & .213 & $\mathbf{. 4 9 8}$ & .376 \\
Financial instability & 2.671 & $\mathbf{. 5 3 8}$ & 2.240 \\
Eigen value & .535 & 1.809 & .449 \\
Total Inertia & 53.514 & .361 & 44.828 \\
\% of Variance & & 36.141 & \\
\hline
\end{tabular}

Table 4. Three-dimensional representation for "sexual unwellness" for Portuguese older adults: factor loadings for each dimension, mean loadings and \% inertia (variance) explained

\begin{tabular}{|c|c|c|c|}
\hline \multirow[b]{2}{*}{ Categories } & \multicolumn{3}{|c|}{ Dimensions } \\
\hline & Daily hassles and health issues & $\begin{array}{l}\text { Poor intimacy and financial } \\
\text { instability }\end{array}$ & Mean \\
\hline Poor sexual health & .439 & .233 & .335 \\
\hline Daily hassles & .713 & .108 & .411 \\
\hline $\begin{array}{c}\text { Lack of intimacy and } \\
\text { affection }\end{array}$ & .304 & .501 & .403 \\
\hline Poor general health & .459 & .438 & .449 \\
\hline Financial instability & .281 & .531 & .406 \\
\hline Eigen value & 2.196 & 1.811 & 2.004 \\
\hline Total Inertia & .531 & .347 & .439 \\
\hline$\%$ of Variance & 53.114 & 34.722 & 43.918 \\
\hline
\end{tabular}

\section{Discussion}

This research contributes to the literature in two ways. Our findings show five themes, as indicators of SU ("poor sexual health", "daily hassles", "lack of intimacy and affection", "poor general health", and "financial instability", which suggested a two-dimensional model for SU for each group of older adults. 
"Lack of intimacy and affection" was the most verbalized indicator of SU for these participants (25.1\%), which corroborates recent literature (Robinson \& Molzahn, 2007). Contrariwise, "poor sexual health" was the least referred indicator of SU (11.2\%), which validates previous studies which stress the pertinence of sexual health in old age (DeLamater \& Sill, 2005). Similarly, English participants pointed out that "lack of intimacy and affection" was the most important indicator of SU (23.3\%), and "poor sexual health" was the least referred indicator of SU (11.8\%). Existing research pointed out that emotional factors, chronic health problems, menopause, low libido, problems of erectile functioning, and overall sexual dysfunctions contribute to SU (Syme et al., 2015). Conversely, in another cross-national study with older adults, affection and care, sexual and physical health were the most prevalent indicators of SWB (von Humboldt et al., 2016).

Portuguese older adults indicated "daily hassles" $(31.0 \%)$ as the most frequent contributor for SU, and "financial instability" (9.4\%) as the least frequent contributor to SU. Literature has suggested that stressors and daily hassles may contribute to decreasing sexual activity, and consequently lowering sexual satisfaction (Bodenmann \& Atkins, 2010). Further studies reported that couples engage in less sex when they are tired and exhausted, and in relation to this, Bodenmann and Atkins (2010) pointed out that daily stressors may trigger stress and tension in the relationship, which in turn may lead to a decrease of sexual libido.

The MCA considering the correlational structure of SU suggests that this concept is explained by a two-factor model, for each nationality. Regarding the English participants, the largest factor "poor affection, intimacy and sexual health" accounted for $53.5 \%$ of total variance, while "poor general health and financial instability" was the least representative factor for these participants ( $36.1 \%$ of total variance). For these older participants, "poor sexual health" and "lack of intimacy and affection" constituted the first factor ("poor affection, intimacy and sexual health").

Older adults continue to enjoy, value, and engage in sexual activity, with more emphasis in sexual touching and less focus on orgasm or sexual intercourse (Galinsky, 2012). Moreover, older adults' well-being is related to a good sexual function (Laumann, Paik, \& Rosen, 1999). Additionally, the lack of intimacy and affection may contribute to SU, when intercourse is no longer possible (Gott \& Hinchliff, 2003).

"Daily hassles", "poor general health" and "financial instability" comprised the second dimension ("poor general health and financial instability"). Literature indicated that older adults can remain sexually interested and capable, even in the presence of physical illness (Moreira, Glasser, \& Gingell, 2005). However, older adults with poor general health reported more sexual problems and were less sexually active (DeLamater \& Karraker, 2009). Indeed, a number of physical and mental health challenges may affect sexual quality of life and diminish or stop sexual activity (DeLamater \& Karraker, 2009). Moreover, and according to Gott (2005), after retirement, some older adults may face a progressive loss of economic autonomy and an increase of financial instability, which may have a negative impact in sexual interest and sexual function. Additionally, financial instability in old age may contribute to conflicts in spousal and family relationships, social discrimination, feelings of guilt and shame towards sexuality, low sexual interest, low SWB and poor self-image (López \& Fuertes, 1999).

As for the Portuguese participants, the largest dimension "daily hassles and health issues" accounted for 53.1\% of total variance, whilst "poor intimacy and financial instability" was the least illustrative dimension for these participants $(34.7 \%$ of total variance).

The first factor ("daily hassles and health issues") comprised "daily hassles" and "poor general health"; hence these older adults were focused on their daily difficulties and on problems concerning their health. We found no studies relating daily hassles and SWB in old age. However, literature indicated that psychological stressors may interfere with sexual function through psychological and physiological mechanisms. Hamilton and Julian (2014) indicated that daily stressors predicted lower scores on sexual satisfaction and sexual activity and that daily stressors, depression, and anxiety were highly correlated with one another. Additionally, older adults with high levels of daily hassles were at an increased risk of dying early, and were more exposed to serious life events (e.g., diseases, incapacity and losing a loved one) (Aldwin et al., 2014).

Moreover, different studies reiterated that physical health, cardiovascular illnesses, diabetes and arthritis may influence the expression of sexuality (Helmes \& Chapman, 2012). In this context, engaging in sexual activities may enhance emotional, psychological and physical well-being and may contribute to reduce several health problems (Trudel, Turgeon, \& Piché, 2010).

The second factor ("poor intimacy and financial instability") comprised "lack of intimacy and affection" and "financial instability"; hence these older adults were less satisfied with their sexual intimacy and affection and were focused on financial difficulties. 
Older adults may view sexuality as an expression of affection and a continuing opportunity for growth and experience (Kalra et al., 2011). Syme and his colleagues (2015) suggested that the lack of sexual partner is a barrier to sexual expression and sexual intimacy. Significant predictors of lack of sexual satisfaction in a different study included being of female gender, lack of satisfaction with marital support, and poorer spousal health. Despite the fact that older adults live within a relatively able social network, which provides regular contact over time, Tsai (2004) suggested that one reason for not discussing sexuality among friends and family is fear of embarrassment. Additionally, research has reiterated both negative and restrictive attitudes regarding sexuality among old adults (Gott, 2005; Hinrichs \& Vacha-Haase, 2010). Moreover, financial stressors and stressors related to low socioeconomic status were related to lower scores on a number of aspects of sexual functioning, in particular for women (Hamilton \& Julian, 2014).

Limitations to this study should be considered when interpreting the outcomes. We used a non-probabilistic sample, thus the findings cannot be generalized to the entire older population. In fact, it only clarifies how the $\mathrm{SU}$ is perceived by this group and provides clues for future research. Sexual orientation information is not available, limiting our ability to understand the effect of being an aging sexual minority on sexual expression.

Although our sample was diverse and cross-national, there is a need for researchers to maximize validity and highpoint other categories using qualitative research. Even though the interviews were conducted with a view to being bias free, one core area was predetermined to be addressed. Future research is needed to better understand the factors that contribute to SU. Therefore, the inclusion of a comprehensive set of multidimensional risk factors for SWB in future studies is recommended.

Apart these limitations, this study represents an important empirical step in understanding how older adults experience SU, being that we found a set of categories that differently contributed to $\mathrm{SU}$ in two nationally-diverse groups of older adults and a distinct two-dimensional model for SU for each group of older adults. Contrary to studies using closed-end questionnaires, this approach allows for insightful gains into the overall nature of the SU.

Sexuality is integral to well-being and successful aging in old age. In order to understand broader aspects of decline in SWB, this study examined the factors that contribute to older adults' SU. Other studies analyzed these factors in isolation, and have often employed a cross-sectional design (Syme et al., 2015).

These user-driven outcomes can form part of future assessment for community-dwelling older adults, which can be used in interventions and health care planning.

Older adults' sexuality is multidimensional and culturally diverse, and should be considered more broadly than other studies that analyzed only at sexual dysfunction or frequency. Additionally, older adults do not spontaneously verbalize their sexual concerns, therefore educational and intervention programs regarding older adults' SU would result in more informed, positive and assertive attitudes towards their concerns. Indeed, education may play an important role concerning sexual expression in late adulthood, and could help professionals to understand the importance of SU in their sexual health, risk factors concerning SWB and the cultural diversity of their concerns.

Hence, we consider the issues about SU to be key aspects for older individuals to age well and that by studying these issues in greater depth, researchers may enlighten nonjudgmentally the value of a healthy and satisfying sexuality.

\section{Acknowledgements}

Conflict of Interest: The authors report no conflicts of interest.

Author Contributions: SVH: study concept and design, analysis and interpretation of data, recruitment of subjects, preparation of manuscript; SS: recruitment of subjects, preparation of manuscript; IL: study concept and design, interpretation of data. All authors read and approved the final manuscript.

This research did not receive any specific grant from funding agencies in the public, commercial, or not-for-profit sectors.

\section{References}

Aldwin, C. M., Jeong, Y. J., Igarashi, H., Choun, S., \& Spiro, A. (2014). Do hassles mediate between life events and mortality in older men? Longitudinal findings from the VA Normative Aging Study. Experimental Gerontology, 59, 74-80. https://doi.org/10.1016/j.exger.2014.06.019

Bodenmann, G., \& Atkins, D. C. (2010). The association between daily stress and sexual activity. Journal of Family Psychology, 24(3), 271-279. https://doi.org/10.1037/a0019365 
DeLamater, J., \& Karraker, A. (2009). Sexual functioning in older adults. Current Psychiatry Reports, 11, 6-11. https://doi.org/10.1007/s11920-009-0002-4

DeLamater, J., \& Sill, M. (2005). Sexual desire in later life. Journal of Sex Research, 42, 138-149. https://doi.org/10.1080/00224490509552267

Fernández-Ballesteros, R. (2010). Quality of life in old age: Problematic issues. Applied Research Quality Life, 6, 21-40. https://doi.org/10.1007/s11482-010-9110-x

Folstein, M. F., Folstein, S. E., \& McHugh, P. R. (1975). Mini-mental state. A practical method for grading the cognitive state of patients for the clinician. Journal of Psychiatric Research, 12, 189-198. https://doi.org/10.1016/0022-3956(75)90026-6

Galinsky, A. M. (2012). Sexual touching and difficulties with sexual arousal and orgasm among U. S. older adults. Archives of Sexual Behavior, 41, 875-890. https://doi.org/10.1007/s10508-011-9873-7

Gott, M. (2005). Sexuality, Sexual Health and ageing. London: Open University Press.

Gott, M., Hinchliff, S., \& Galena, E. (2004). General practitioner attitudes to discussing sexual health issues with $\begin{array}{lllll}\text { older people. Social Science \& } & \text { 2093-2103. }\end{array}$ https://doi.org/10.1016/j.socscimed.2003.08.025

Gurvinder, K., Subramanyam, A., \& Pinto, C. (2011). Sexuality: Desire, activity and intimacy in the elderly. Indian Journal Psychiatry, 53(4), 300-306. https://doi.org/10.4103/0019-5545.91902

Hamilton, L. D., \& Julian, A. M. (2014). The relationship between daily hassles and sexual function in men and women. Journal of Sex \& Marital Therapy, 40(5), 379-395. https://doi.org/10.1080/0092623X.2013.864364

Helmes, E., \& Chapman, J. (2012). Education about sexuality in the elderly by healthcare professionals: A survey from the Southern Hemisphere. Sex Education, 12(1), 95-107. https://doi.org/10.1080/14681811.2011.601172

Hinrichs, K., \& Vacha-Haase, T. (2010). Staff perceptions of same-gender sexual contacts in long-term care facilities. Journal of Homosexuality, 57(6), 776-789. https://doi.org/10.1080/00918369.2010.485877

Hirayama, R., \& Walker, A. J. (2011). Who helps older adults with sexual problems? Confidants versus physicians. Journals of Gerontology Series B: Psychological Sciences and Social Sciences, 66B(1), 109-118. https://doi.org/10.1093/geronb/gbq021

Hooghe, M. (2012). Is Sexual well-Being part of subjetive well-being? An empirical analysis of Belgian (Flemish) survey data using an extended well-being scale. Journal of Sex Research, 49(2-3), 264-273. https://doi.org/10.1080/00224499.2010.551791

Hsieh, H., \& Shannon, S. E. (2015). Three approaches to qualitative content analysis. Qualitative Health Research, 15(9), 1277-1288. https://doi.org/10.1177/1049732305276687

Laumann, E. O., Paik, A., \& Rosen, R. C. (1999). Sexual dysfunction in the United States. Journal of the American Medical Association, 281, 537-544. https://doi.org/10.1001/jama.281.6.537

Laumann, E. O., Paik, A., Glasser, D. B., Kang, J., Wang, T., Levinson, B., ... Gingell, C. (2006). A cross-national study of subjective sexual well-being among older women and men: Findings from the global study of sexual attitudes and behaviors. Archive of Sexual Behavior, 35(2), 145-161. https://doi.org/10.1007/s10508-005-9005-3

Lee, D. M., Nazroo, J., O'Connor, D. B., Blake, M., \& Pendleton, N. (2014). Sexual Health and Well-being among Older Men and Women in England: Findings from the English Longitudinal Study of Ageing. Archives of Sexual Behavior, 45(1), 133-144. https://doi.org/10.1007/s10508-014-0465-1

López, F., \& Fuertes, A. (1999). Para compreender a sexualidade [Understanding sexuality]. Lisboa: Associação para o Planeamento da Família.

Moreira, E., Glasser, D., \& Gingell, C. (2005). Sexual activity, sexual dysfunction and associated help-seeking behaviours in middle-aged and older adults in Spain: A population survey. World J Urol, 23(6), 422-429. https://doi.org/10.1007/s00345-005-0035-1

Robinson, J. G., \& Molzahn, A. E. (2007). Sexuality and quality of life. Journal of Gerontological Nursing, $33(3), 19-27$. 
Rosen, R. C., \& Bachmann, G. A. (2008). Sexual well-being, happiness, and satisfaction, in women: The case for a new conceptual paradigm. Journal of Sex and Marital Therapy, 34, 291-297. https://doi.org/10.1080/00926230802096234

Schwartz, P., Diefendorf, S., \& McGlynn-Wright, A. (2014). Sexuality in Aging. In D. L. Tolman, \& L. M. Diamond (Eds.), APA Handbook of Sexuality and Psychology: Person-Based Approaches (Vol. 1, pp. 523-551). Washington: American Psychological Association. https://doi.org/10.1037/14193-017

Syme, M. L., Cordes, C. C., Cameron, R. P., \& Mona, L. R. (2015). Sexual health and well-being in the context of aging. In. P. A. Lichtenberg, \& B. Carpenter (Eds.), APA Handbook of Clinical Geropsychology. Washington DC: American Psychological Association. https://doi.org/10.1037/14459-015

Trudel, G., Trugeon, L., \& Piché, L. (2010). Marital and sexual aspects of old age. Sexual and Relationship Therapy, 25(3), 316-341. https://doi.org/10.1080/14681991003750467

Tsai, Y. (2004). Nurses' facilitators and barriers for taking a sexual history in Taiwan. Applied Nursing Research, 17(4), 257-264. https://doi.org/10.1016/j.apnr.2004.09.011

von Humboldt, S., Leal, I., \& Monteiro, A. (2016). Are older adults well sexually? Sexual well-being among a cross-national sample of older adults. Review of European Studies, 8(1), 134-144. https://doi.org/10.5539/res.v8n1p134

\section{Copyrights}

Copyright for this article is retained by the author(s), with first publication rights granted to the journal.

This is an open-access article distributed under the terms and conditions of the Creative Commons Attribution license (http://creativecommons.org/licenses/by/4.0/). 